\title{
Time-intensity profile of pitanga nectar (Eugenia uniflora L.) with different sweeteners: Sweetness and bitterness
}

\author{
Mírian Luisa Faria Freitas ${ }^{1}$, Mariana Borges de Lima Dutra ${ }^{2}$ and \\ Helena Maria André Bolini ${ }^{3}$
}

\begin{abstract}
Pitanga has been used by the Brazilian food industry mainly for juice production. This fruit shows good economic potential due to its high concentration of vitamins and minerals. The aim of the present work was to characterize the time-intensity profile of pitanga nectar sweetened with different sweeteners to verify differences on the perception of sweet and bitter tastes. The sweeteners used to replace sucrose were sucralose, aspartame, stevia 40\% rebaudioside A, stevia 95\% rebaudioside A, neotame, and 2:1 cyclamate/saccharin blend. Fifteen assessors were selected according to their discriminating capability and trained to participate in the time-intensity analysis for sweetness and bitterness. The samples prepared with sucralose and 2:1 cyclamate/saccharin blend presented a similar sweetness profile to the sample prepared with sucrose, and the samples prepared with sucralose and aspartame presented a similar bitterness profile to the sample prepared with sucrose. Thus, sucralose would be the most suitable sweetener to replace sucrose in pitanga nectar.
\end{abstract}

\section{Keywords}

Tropical fruit, descriptive sensory analysis, low-calorie beverage, principal component analysis

Date received: 7 September 2014; revised: 28 November 2014; accepted: 19 December 2014

\section{INTRODUCTION}

Pitanga (Eugenia uniflora L.), also known as "surinam cherry" or "Brazilian cherry," is a tropical fruit which belongs to the Myrtaceae family (Bezerra et al., 2000; Gomes, 1975). It contains high carotenoid levels (32\% of total carotenoid is lycopene) and significant amounts of vitamin A and vitamin C (Lima et al., 2002).

Due to the large Brazilian production, pitanga can also be used in the food industry. In Brazil, the largest commercial scale crop, which is also the largest in Latin America, is located in the state of Pernambuco, and the state annual production is estimated to be 1300-1700 ton/year (Silva, 2006). Pitanga has been mainly used for juice production by the Brazilian

Food Science and Technology International 22(1) 58-67

(C) The Author(s) 2015 Reprints and permissions:

sagepub.co.uk/journalsPermissions.nav

DOI: $10.1177 / 1082013214568795$

fst.sagepub.com

ऽAGE food industry. It shows good economic potential due to its high concentration of vitamins and minerals (Lima et al., 2002).

There is a growing trend towards the consumption of diet and light products, which are indicated, among other purposes, for people with diabetes or other medical restrictions, including obesity, and for people who are concerned with aesthetics and health (Cardoso

\footnotetext{
${ }^{1}$ Department of Food Engineering and Technology, State University of São Paulo, São Paulo, Brazil

${ }^{2}$ National Institute of Education, Science and Technology of the South of Minas Gerais State, Minas Gerais, Brazil

${ }^{3}$ Department of Food and Nutrition, University of Campinas, São Paulo, Brazil
}

\section{Corresponding author:}

Mírian Luisa Faria Freitas, Department of Food Engineering and Technology, UNESP - University of the State of São Paulo, 2265 Cristóvão Colombo Street, Jardim Nazareth, Sao José do Rio Preto, São Paulo 15.054-000, Brazil.

Email: mirianlfreitas@yahoo.com.br 
and Bolini, 2007; Souza et al., 2013). With increased consumer interest in reducing sugar intake, food products made with sweeteners rather than sugar have become more popular (Pinheiro et al., 2005). For this reason, the formulation of products by replacing sucrose and the knowledge of their sensory properties are of high interest to food science research in order to develop increased product options for people who want or need to consume this type of food (Palazzo and Bolini, 2014).

According to Montijano et al. (1998), sweeteners comprise the group of substances used to replace sucrose, which share the property of interacting with taste receptors and produce the sensation perceived and named as sweet. One of the reasons for using high-intensity sweeteners is to find types of sweeteners which can offer the same sweet taste as sucrose, but with fewer calories. Sensory properties which are evaluated for sweeteners include the intensity and pleasantness of sweet or bitter tastes, the presence of aftertastes, etc. It is important both for consumers and food producers that the sweetener used has a similar sensory profile to the profile of sucrose (Čmejlová et al., 2009). However, replacing sucrose by alternative sweeteners can change the perception of bitter and sweet tastes (Bolini-Cardello et al., 1999). It is important for the sweet taste not to have a delay of the initial onset, and not to linger afterwards (Čmejlová et al., 2009).

Time-intensity analysis is an extension to the descriptive sensory analysis, providing temporal information about perceived sensations in food (Cliff and Heymann, 1993). This type of test was described by Amerine et al. (1965) as the measurement of the rate, duration, and intensity perceived in a single sensation.

As assessors are continuously monitoring their perceived sensations, from the beginning to the end, the sensory researcher is apt to quantify the continuous perception changes that occur in the respective attribute over time. When several attributes are analyzed, the flavor or texture profile of a complex food can show differences between products that change over time (Alves et al., 2008; Cliff and Heymann, 1993; Lawless and Heymann, 1999). Using time-intensity analysis, it is possible to verify the beginning of the perception of maximum intensity or the decline of important attributes to the consumer in specific products. Timeintensity analysis must be applied in studies to replace ingredients in each type of product because this allows us to show clearly that the substitution of materials promote the modification of the time-intensity profile during the time of consumption differently in each attribute analyzed and each type of food (Palazzo and Bolini, 2014).

This sensory technique has been used to analyze many food matrices, such as mixed fruit jam (Souza et al., 2013), white wine (Sokolowsky and Fischer, 2012), gluten-free bread (Morais et al., 2013), mango juice (Cavallini and Bolini, 2005), ice cream (Cadena and Bolini, 2011), strawberry jam (Alves et al., 2008), raspberry-flavored gelatin (Palazzo and Bolini, 2009), chocolate (Palazzo and Bolini, 2014), and olive oil (Sinesio et al., 2005), thus showing the importance of such technique in sensory evaluation of food.

Although some studies have been performed previously, there is still a lack of data regarding the processing of tropical fruits, including pitanga (Ongaratto and Viotto, 2009). And, there are no studies about sweetness and bitterness profile of pitanga nectar. In this context, the aim of the present work was to characterize the time-intensity profile of pitanga nectar sweetened with seven different sweeteners to verify differences on the perception of sweet and bitter tastes.

\section{MATERIALS AND METHODS}

\section{Materials}

The pitanga nectar samples were prepared with unsweetened frozen pulp (Ricaeli, Cabreúva, Brazil), drinking water, and different sweeteners: sucrose (União, São Paulo, Brazil), sucralose (TovaniBenzaquem, São Paulo, Brazil), aspartame (All Chemistry do Brasil, São Paulo, Brazil), stevia 40\% rebaudioside A (Clariant, Suzano, Brazil), stevia 95\% rebaudioside A (Tovani-Benzaquem, São Paulo, Brazil), neotame (Sweetmix, Sorocaba, Brazil), and a blend (2:1) of cyclamate (Sweetmix, Sorocaba, Brazil)/ saccharin (Pharma Nostra, Rio de Janeiro, Brazil).

\section{Methods}

Sample preparation. Seven pitanga nectar samples were prepared in the Laboratory of Sensory Science and Consumer Research of the School of Food Engineering (UNICAMP/Campinas/Brazil) the day before each test. Frozen pulp, drinking water, and sweeteners were used. The ideal pulp dilution $(25 \%$ pulp) and ideal sweetness with sucrose (10\% sucrose) were previously determined by consumers using a justabout-right scale (Freitas et al., 2014). The equi-sweet concentrations of sweeteners were also previously determined by assessors, by using the magnitude estimation model. Sweetener concentrations to replace sucrose were $0.016 \%$ sucralose, $0.0541 \%$ aspartame, $0.1 \%$ stevia $40 \%$ rebaudioside A, $0.1 \%$ stevia $95 \%$ rebaudioside $\mathrm{A}, 0.0017 \%$ neotame, and $0.036 \% \quad 2: 1$ cyclamate/saccharin blend (Freitas et al., 2014). Each sample was sweetened with the respective sweetener and homogenized for about $2 \mathrm{~min}$. The samples were stored in bottles in a refrigerator (about $10^{\circ} \mathrm{C}$ ) until the moment of sensory analysis. 
Sensory analyses. Tests were conducted in individual booths at the Laboratory of Sensory Science and Consumer Research of the School of Food Engineering (UNICAMP/Campinas/Brazil). Sessions were carried out in individual air conditioned $\left(22^{\circ} \mathrm{C}\right)$ booths with white light. Water was provided for palate cleansing. Samples were presented in balanced complete blocks (Macfie et al., 1989) in disposable plastic cups coded with a three-digit number. This research project was submitted to and approved by the Research Ethics Committee from the University of Campinas, CEP n ${ }^{\circ} 1264 / 2011$. Moreover, a Term of Consent containing information about the research was prepared and presented to the assessors.

Pre-selection of assessors. During the pre-selection, several candidates were evaluated by Wald's sequential analysis using triangle tests (Amerine et al., 1965) to select potential assessors with high discrimination ability. Two pitanga nectar samples were prepared (using $25 \%$ pulp with $3.5 \%$ and $5.0 \%$ sucrose) and previously tested to obtain a $0.1 \%$ significant difference level. The following parameters were used in the sequential analysis to select the candidates: $\rho_{0}=0.33$ (maximum acceptable inability), $\rho_{1}=0.66$ (minimum acceptable ability), $\alpha=0.05$ (probability of accepting a candidate without sensory acuity) and $\beta=0.05$ (probability of rejecting a candidate with sensory acuity; Augusto et al., 2005; Moraes and Bolini, 2010). After the preselection, 19 potential assessors were chosen.

Training session. References of maximum intensity for sweet and bitter tastes were determined and are presented in Table 1. Training for the formation of sensory memory and equalization among the assessors was carried out by direct contact of the potential assessors with the references (Cadena and Bolini, 2011). These assessors were trained in three 30 -min sessions.
Selection of assessors. The 19 pre-selected and trained potential assessors analyzed the seven samples with respect to sweetness and bitterness in four repetitions using the time-intensity method. In the selection of the assessors for the TI assessment, the analysis of variance (ANOVA) was applied for each assessor and each parameter in each sensation separately, and 15 assessors were selected to participate according to their discriminating capability $(p<0.50)$ and repeatability $(p>0.05)$. Moreover, an individual consensus was also considered by verifying each curve separately in relation to each parameter for each attribute (Damásio and Costell, 1991).

Time-intensity analyses. Time-intensity analyses were performed according to the Standard Guide for TimeIntensity Evaluation of Sensory Attributes (ASTM, 2011) for the sweet and bitter tastes. These two attributes, which are directly affected when replacing sucrose by sweeteners, were evaluated separately in three repetitions.

The tests were carried out using a structured linear scale from zero to $10 \quad(0=$ none, $5=$ moderate, $10=$ strong), and the standardized conditions for analysis of the attributes were as it follows: assessors' wait time, $10 \mathrm{~s}$; time with sample in the mouth, $10 \mathrm{~s}$; and time after swallowing, $90 \mathrm{~s}$. On hearing the first signal given by the computer, the assessor took the full amount of the sample in his or her mouth and, using the mouse, indicated on the scale the intensity of the attribute. On hearing the second signal, the assessor swallowed the sample and, using the mouse, he or she recorded on the scale the intensity of the attribute according to the time spent, while a third signal indicated the end of the test (Morais et al., 2013).

Data collection for the time-intensity analyses was carried out on a computer using the software TimeIntensity Analysis of Food and Tastes (TIAFT)

Table 1. Definitions and references for the sensations evaluated by potential assessors for pitanga nectar in time-intensity analysis

\begin{tabular}{lll}
\hline Sensation & Definition & Reference \\
\hline Sweetness & Characteristic taste of sucrose & None: - \\
& & $\begin{array}{c}\text { Strong: pitanga nectar pre- } \\
\text { pared with } 25 \% \text { pulp and } \\
12 \% \text { sucrose }\end{array}$ \\
Bitterness & & None: - \\
& Characteristic taste of stevia & Strong: pitanga nectar pre- \\
& & pared with $25 \%$ pulp and \\
& & $0.12 \%$ stevia $40 \%$ rebau- \\
& & dioside A \\
\hline
\end{tabular}


Table 2. Means of the parameters of time-intensity curves for sweetness for pitanga nectar samples

\begin{tabular}{|c|c|c|c|c|c|c|c|}
\hline \multirow[b]{2}{*}{ Parameters } & \multicolumn{7}{|l|}{ Samples } \\
\hline & Sucrose & Sucralose & Aspartame & Stevia $40 \%$ reb & Stevia $95 \%$ reb & Neotame & Cyclamate/Saccharin 2:1 \\
\hline$I_{\max }$ & $6.68 d$ & $6.85 \mathrm{c}, \mathrm{d}$ & $7.41 \mathrm{~b}, \mathrm{c}$ & $7.43 \mathrm{~b}, \mathrm{c}$ & $7.62 b$ & $8.34 \mathrm{a}$ & $6.60 \mathrm{~d}$ \\
\hline $\mathrm{Ti}_{\max }$ & $13.95 a$ & $13.56 \mathrm{a}$ & $13.77 \mathrm{a}$ & $14.21 \mathrm{a}$ & $14.22 \mathrm{a}$ & $14.09 a$ & $12.50 \mathrm{a}$ \\
\hline Area & $157.57 \mathrm{c}$ & $158.36 \mathrm{c}$ & $203.39 b$ & $233.76 b$ & $235.56 b$ & 299.98 a & $146.45 c$ \\
\hline $\mathrm{T}_{\text {tot }}$ & $38.98 \mathrm{c}$ & $41.86 \mathrm{c}$ & $45.68 b, c$ & $52.27 b$ & $51.74 b$ & $60.37 \mathrm{a}$ & $38.79 \mathrm{c}$ \\
\hline
\end{tabular}

reb, rebaudioside $A$.

Means with letters in common in the same line do not differ statistically $(p \leq 0.05)$ according to Tukey's means test.

(Universidade Estadual de Campinas - UNICAMP, 2012). The time-intensity parameters of interest were $\mathrm{I}_{\max }$ (maximum intensity recorded by the judge), $\mathrm{Ti}_{\max }$ (time at which the maximum intensity was recorded), Area (area of time vs. intensity curve) and $\mathrm{T}_{\text {tot }}$ (total duration time of the sensation) (Morais et al., 2013; Palazzo and Bolini, 2014).

Statistical analyses. The parameters obtained by timeintensity curves in relation to each attribute were evaluated separately by two-way ANOVA (ASTM, 2011; Stamatis, 2002), Tukey's means test (at 5\% significance) and principal components analysis (PCA). The statistical software used was the Statistical Analysis System (SAS, 2012).

The original data did not suffer any pre-treatment, such as centralization or normalization. The application of non-centered PCA, using the original curves, was preferred due presenting more relevant information, that is, it retain information about level and variability in the analysis (Sinesio et al., 2005; Techakriengkrai et al., 2004). The first principal component non-centered has the best characteristics of time-intensity curves, and the second principal component non-centered can be interpreted as the rate of increase and decrease of the time-intensity curves (Cerqueira Júnior et al., 2007; Dijksterhuis et al., 1994).

\section{RESULTS AND DISCUSSION \\ Time-intensity analysis for sweetness of pitanga nectar}

The means of the scores given by the team of assessors for sweetness are presented in Table 2.

By analyzing Table 2, it is possible to notice that samples do not differ significantly $(p \leq 0.05)$ in relation to the maximum time-intensity $\left(\mathrm{Ti}_{\max }\right)$. To what the parameters maximum intensity $\left(\mathrm{I}_{\max }\right)$, total sensation area (Area), and total sensation time $\left(\mathrm{T}_{\text {tot }}\right)$ are concerned, the sample which showed the highest mean was the one prepared with neotame, which differed significantly from the others $(p \leq 0.05)$. The samples prepared with stevia $95 \%$ rebaudioside A, stevia $40 \%$ rebaudioside $\mathrm{A}$, and aspartame presented intermediate means, and they did not differ significantly among them $(p \leq 0.05)$. On the other hand, the samples prepared with cyclamate/saccharin 2:1, sucralose, and sucrose presented the lowest means and did not differ significantly among them $(p \leq 0.05)$.

The PCA of data from time-intensity analysis allows the common information of the assessors to be taken with more relevance than information due to deviations of response (Cerqueira Júnior et al., 2007). In addition, it shows which of the parameters of the time-intensity curves are relevant to present a map of perception of the samples, and it can establish the variability between the respective studied sensations (Palazzo and Bolini, 2014; Sinesio et al., 2005).

The PCA graph for sweetness of pitanga nectar is presented in Figure 1. The principal components 1 and 2 explain $94.72 \%$ of the sample variability. The points of the samples show the average of the repetitions, and the length and direction of the vectors show that all parameters have influenced the principal component 1 and the time parameter for maximum intensity $\left(\mathrm{Ti}_{\text {max }}\right)$ has influenced the principal component 2 the most.

The samples prepared with cyclamate/saccharin 2:1 and neotame are far away from each other, representing different profiles for this sensation. In fact, the sample prepared with cyclamate/saccharin 2:1 obtained the lowest mean in all parameters which were analyzed by Tukey's means test (Table 2), although it did not show a significant difference $(p \leq 0.05)$ with the samples prepared with sucrose and sucralose. Considering only the principal component 1 (responsible for $80.40 \%$ of samples variability), these three samples are close, representing a similar profile.

On the other hand, the sample prepared with neotame obtained the highest mean in all parameters analyzed through Tukey's means test (Table 2), except for the maximum intensity time (Timax). In accordance with that result, in Figure 1 (PCA Graph), the sample prepared with neotame is towards the maximum intensity $\left(I_{\max }\right)$, the total sensation area (Area), and the total 


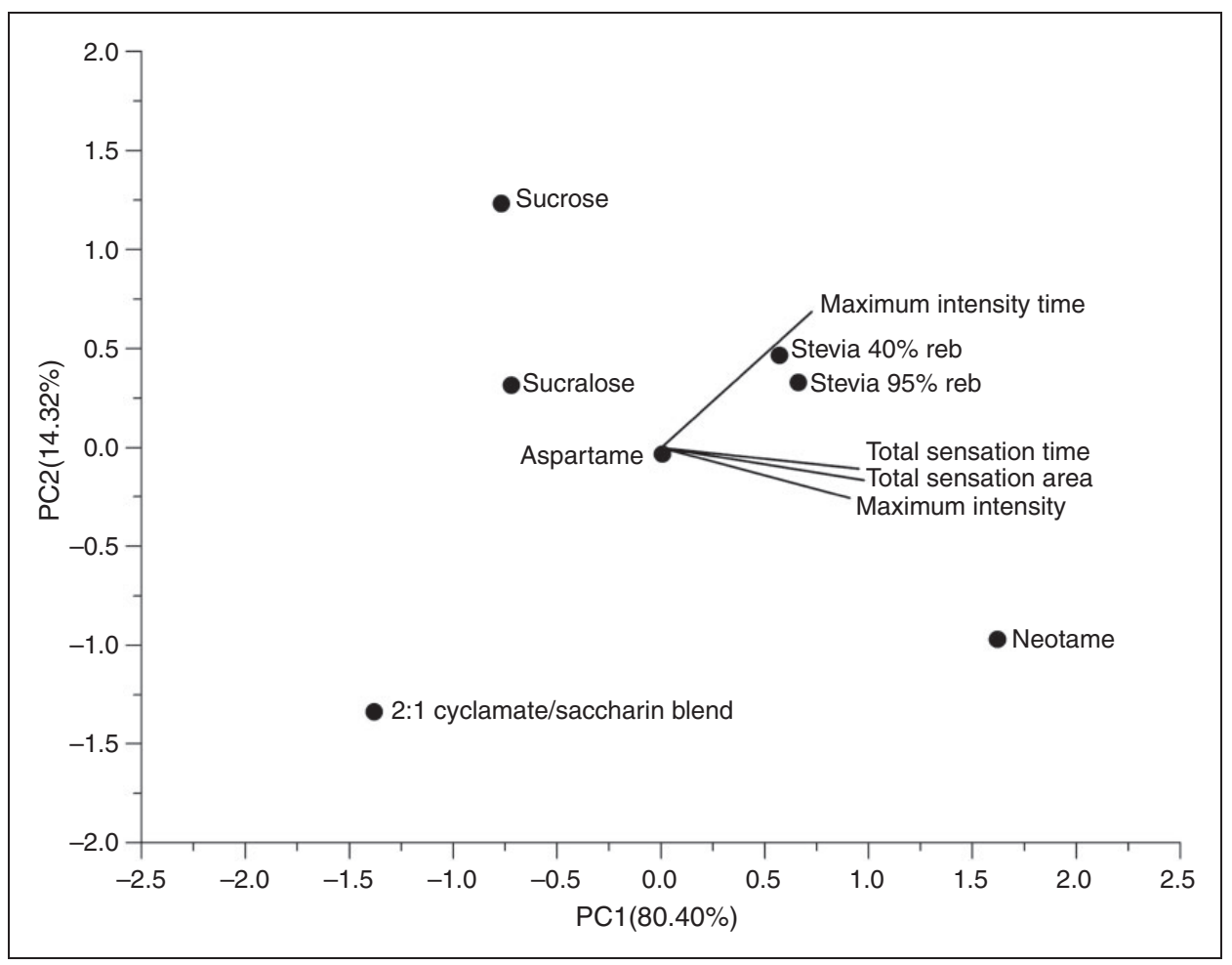

Figure 1. Principal component analysis of sweetness for samples of pitanga nectar.

sensation time $\left(\mathrm{T}_{\text {tot }}\right)$ vectors, and it is characterized by them.

The samples prepared with stevia $95 \%$ rebaudioside A, and with stevia $40 \%$ rebaudioside A were close to each other, which shows that they have a similar profile for sweetness and are characterized by the parameter maximum intensity time $\left(\mathrm{Ti}_{\max }\right)$. Through Tukey's means test (Table 2), these samples obtained the highest means for this attribute, whereas they did not differ significantly from the other samples $(p \leq 0.05)$.

On the opposite side of this graph, there are the samples prepared with sucrose and sucralose, which are close to each other and far away from the vectors which represent the parameters of the time-intensity curve. This shows that they have similar profiles to the sweetness, and they are not characterized by the high intensity or duration of the sensation. The sample of pitanga nectar prepared with aspartame is in the middle of the graph and relatively close to the vectors which represent the parameters for sweetness. In fact, this sample presented intermediate means (Table 2).

The graph in Figure 2 represents the time-intensity curves of pitanga nectar samples related to sweetness.

It is possible to notice that the sample prepared with neotame was the highest in intensity and duration of this sensation. The curves for the samples prepared with stevia $95 \%$ rebaudioside A and with stevia $40 \%$ rebaudioside A overlapped both on the intensity axis and the duration axis. The same happened to the samples prepared with sucrose and cyclamate/saccharin 2:1, whereas these showed the lowest intensity and duration levels. The sample prepared with sucralose has the same intensity level as the samples prepared with sucrose and cyclamate/saccharin $2: 1$, but it has a bit longer sweetness duration time. On the other hand, the sample prepared with aspartame has the same intensity level as the samples prepared with stevias, but it has a little shorter sweetness duration time.

The pitanga nectar samples that presented the highest sweetness duration levels were prepared with neotame and stevias, showing that they have a sweet residual taste. The samples prepared with sucralose, aspartame, and cyclamate/saccharin 2:1 showed the shortest sweetness duration, duration of time similar to that of the sucrose sample.

\section{Time-intensity analysis for bitterness of pitanga nectar}

The means of the scores given by the team for bitterness are shown on Table 3.

By analyzing Table 3, it is verified that the pitanga nectar samples were significantly different $(p \leq 0.05)$ for all parameters assessed in the timeintensity curve. 


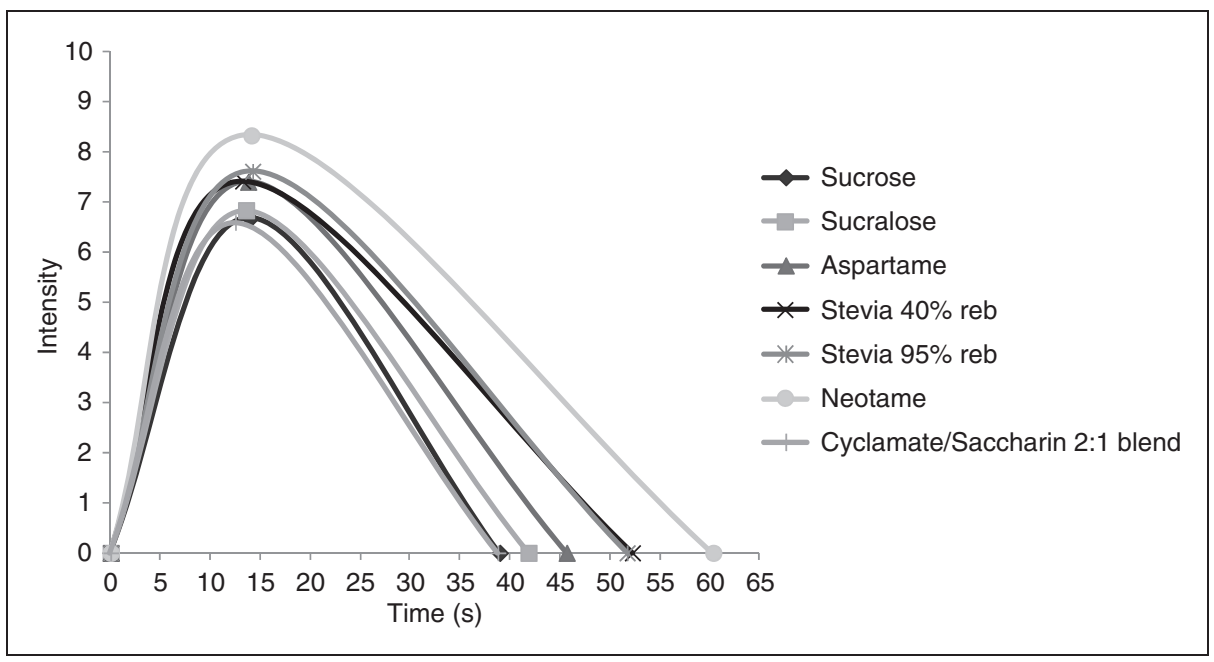

Figure 2. Time-intensity curves and characteristics of sweetness for samples of pitanga nectar.

Table 3. Means of the parameters of time-intensity curves for bitterness from pitanga nectar samples

\begin{tabular}{llllllll}
\hline \multicolumn{7}{c}{ Samples } & \multicolumn{1}{l}{} \\
\cline { 2 - 8 } Parameters & Sucrose & Sucralose & Aspartame & Stevia 40\% reb & Stevia 95\% reb & Neotame & Cyclamate/Saccharin 2:1 \\
\hline $\mathrm{I}_{\max }$ & $3.96 \mathrm{c}$ & $4.74 \mathrm{c}$ & $4.65 \mathrm{c}$ & $7.90 \mathrm{a}$ & $7.45 \mathrm{a}$ & $6.24 \mathrm{~b}$ & $6.01 \mathrm{~b}$ \\
$\mathrm{Ti}_{\max }$ & $13.17 \mathrm{a}, \mathrm{b}$ & $14.54 \mathrm{a}, \mathrm{b}$ & $13.13 \mathrm{~b}$ & $14.68 \mathrm{a}, \mathrm{b}$ & $15.08 \mathrm{a}$ & $13.99 \mathrm{a}, \mathrm{b}$ & $15.05 \mathrm{a}, \mathrm{b}$ \\
Area & $61.26 \mathrm{c}$ & $87.76 \mathrm{c}$ & $79.54 \mathrm{c}$ & $194.66 \mathrm{a}$ & $165.46 \mathrm{a}$ & $124.39 \mathrm{~b}$ & $121.80 \mathrm{~b}$ \\
$\mathrm{~T}_{\text {tot }}$ & $22.69 \mathrm{e}$ & $27.39 \mathrm{~d}, \mathrm{e}$ & $26.92 \mathrm{~d}, \mathrm{e}$ & $42.52 \mathrm{a}$ & $38.91 \mathrm{a}, \mathrm{b}$ & $31.99 \mathrm{c}, \mathrm{d}$ & $33.27 \mathrm{~b}, \mathrm{c}$ \\
\hline
\end{tabular}

Means with letters in common in the same line do not differ statistically $(p \leq 0.05)$ according to Tukey's means test.

To what the maximum intensity $\left(\mathrm{I}_{\mathrm{max}}\right)$, total sensation area (Area), and total sensation time $\left(\mathrm{T}_{\text {tot }}\right)$ parameters are concerned, the samples that presented the highest means had been prepared with stevia $40 \%$ rebaudioside $\mathrm{A}$, and stevia $95 \%$ rebaudioside $\mathrm{A}$, and they did not differ significantly between them $(p \leq 0.05)$, but they differed significantly from the others. The samples that presented the lowest means to these parameters had been prepared with sucrose, aspartame, and sucralose, and they did not differ significantly between them $(p \leq 0.05)$, but they differed significantly from the others. To what the maximum intensity time parameter $\left(\mathrm{Ti}_{\max }\right)$ is concerned, the sample prepared with stevia $95 \%$ rebaudioside A obtained the highest mean, but it did not differ significantly $(p \leq 0.05)$ from the samples prepared with stevia $40 \%$ rebaudioside A, cyclamate/saccharin 2:1, neotame, sucralose, or sucrose.

The pitanga nectar sample prepared with sucrose obtained the lowest mean to the attributes maximum intensity $\left(I_{\max }\right)$, total sensation area (Area), and total sensation time $\left(\mathrm{T}_{\mathrm{tot}}\right)$. However, none of these parameters showed a null mean, which indicates that the pitanga nectar has a characteristic bitterness of the fruit and that it had been intensified by some edulcorants, although it had not been a result of these alone.

Figure 3 shows the graph of PCA, designed to present the results of bitterness time-intensity analysis.

Principal components 1 and 2 explained $98.98 \%$ of samples variability. The points show the average of the repetitions, and the length and direction of the vectors indicate that all parameters influenced the principal component 1 , and the parameter time to maximum intensity $\left(\mathrm{Ti}_{\max }\right)$ was the one which influenced the principal component 2 the most (Figure 3).

The pitanga nectar sample which was prepared with stevia $40 \%$ rebaudioside $\mathrm{A}$ is far away from the others, characterizing a different profile for bitterness. This result is in accordance with the others, because although it did not differ significantly $(p \leq 0.05)$ from the sample prepared with stevia $95 \%$ rebaudioside A, the highest values for maximum intensity parameter $\left(I_{\max }\right)$, total sensation area (Area) and total sensation time $\left(\mathrm{T}_{\text {tot }}\right)$ were attributed to it with the Tukey's means test for bitterness parameters (Table 3). Also, in 


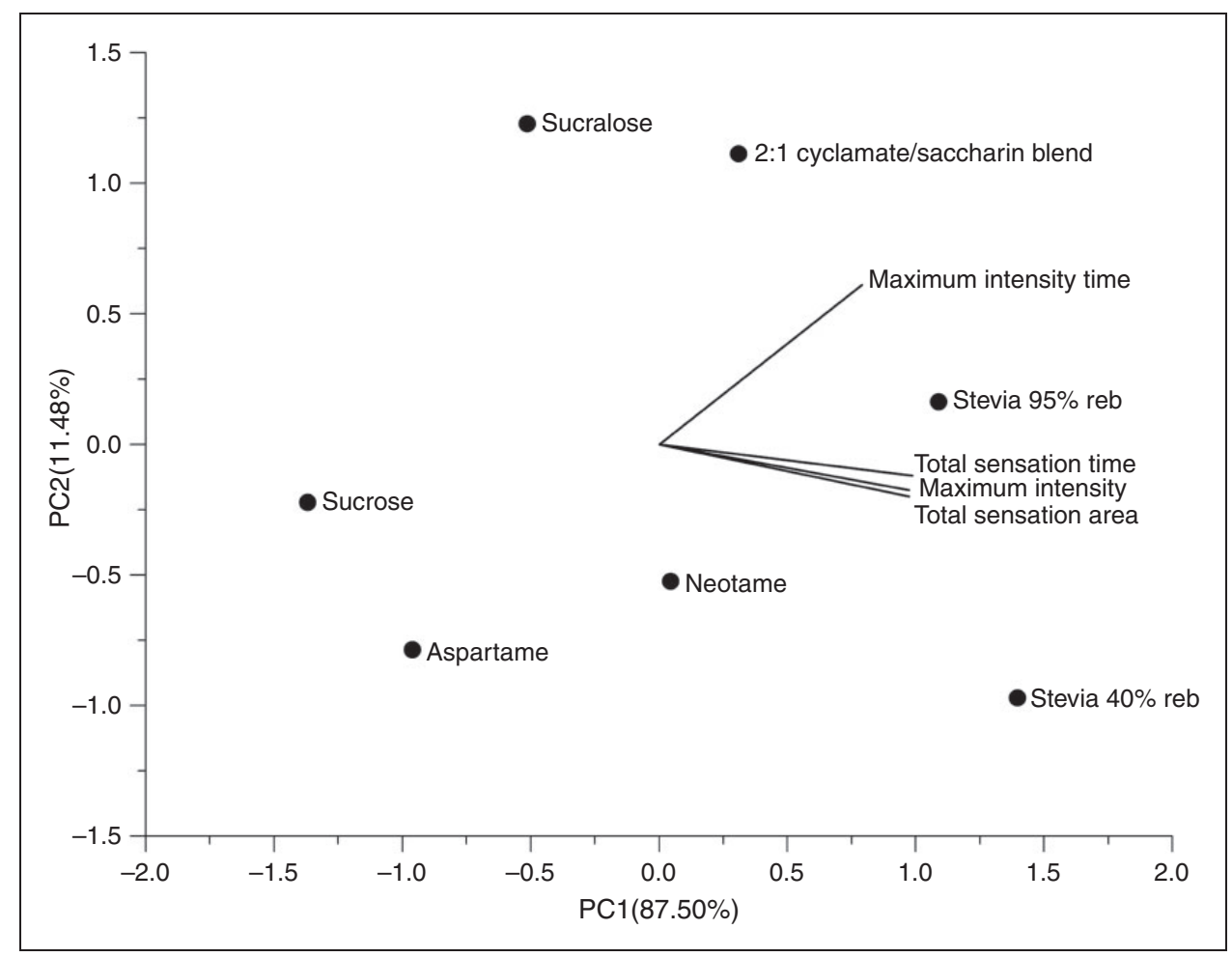

Figure 3. Principal component analysis of bitterness for samples of pitanga nectar.

accordance with this result, Ye et al. (2014) says that the residual intrinsic bitter taste of stevioside, an extract from the stevia leaves, is a limiting factor to its application as a high-intensity edulcorant.

The samples prepared with stevia $95 \%$ rebaudioside A, neotame, and cyclamate/saccharin 2:1 are close, which shows that they have similar profiles for bitterness. Besides, they are close to the vectors that represent the parameters of the time-intensity curve for that sensation, showing that the samples have relevant characteristics for the bitter taste's intensity and duration.

On the other hand, the samples prepared with sucrose, sucralose, and aspartame are on the opposite side from the vectors that represent the parameters of the time-intensity curve for bitterness, which shows that they are not strongly characterized by the intensity and duration attributes for this sensation. In fact, these samples had the lowest scores for the maximum intensity $\left(\mathrm{I}_{\max }\right)$, total sensation area (Area), and total sensation time $\left(\mathrm{T}_{\text {tot }}\right)$ parameters (Table 3$)$.

The graph in Figure 4 shows the time-intensity curves for the pitanga nectar samples related to bitterness.

According to Figure 4, the pitanga nectar samples which were prepared with stevia $40 \%$ rebaudioside A, and stevia $95 \%$ rebaudioside A were the highest in intensity and duration of bitterness. Besides the bitter taste, there was also the presence of residual bitter taste. The sample prepared with stevia $40 \%$ rebaudioside A showed higher figures for the intensity and duration of this sensation, but it did not differ significantly from stevia $95 \%$ rebaudioside A to what the curve parameters from Tukey's means test are concerned (Table 3).

The samples prepared with neotame and cyclamate/ saccharin 2:1 had very similar time-intensity curves, the bitterness's intensity and duration being intermediate, and the bitter and residual taste being medium. The samples prepared with sucralose and aspartame also showed similar curves. However, the sample prepared with sucrose had both lower sensation intensity and duration.

It is possible to notice that the samples prepared with sucralose and aspartame showed similar bitterness characteristics to that prepared with sucrose, showing the bitter taste which is characteristic of the pitanga. Besides, they did not differ significantly in relation to the curve parameters to the bitter sensation from Tukey's means test (Table 3).

Although the stevias used to prepare the samples of pitanga nectar had a big difference in rebaudiosides, they did not differ significantly $(p \leq 0.05)$ to what the duration and intensity of bitterness and sweetness were concerned, as it was expected. According to the literature, rebaudioside $\mathrm{A}$ is sweeter than stevioside (Goyal et al., 2010; Lemus-Mondaca et al., 2012). The product's acidity was probably a factor that 


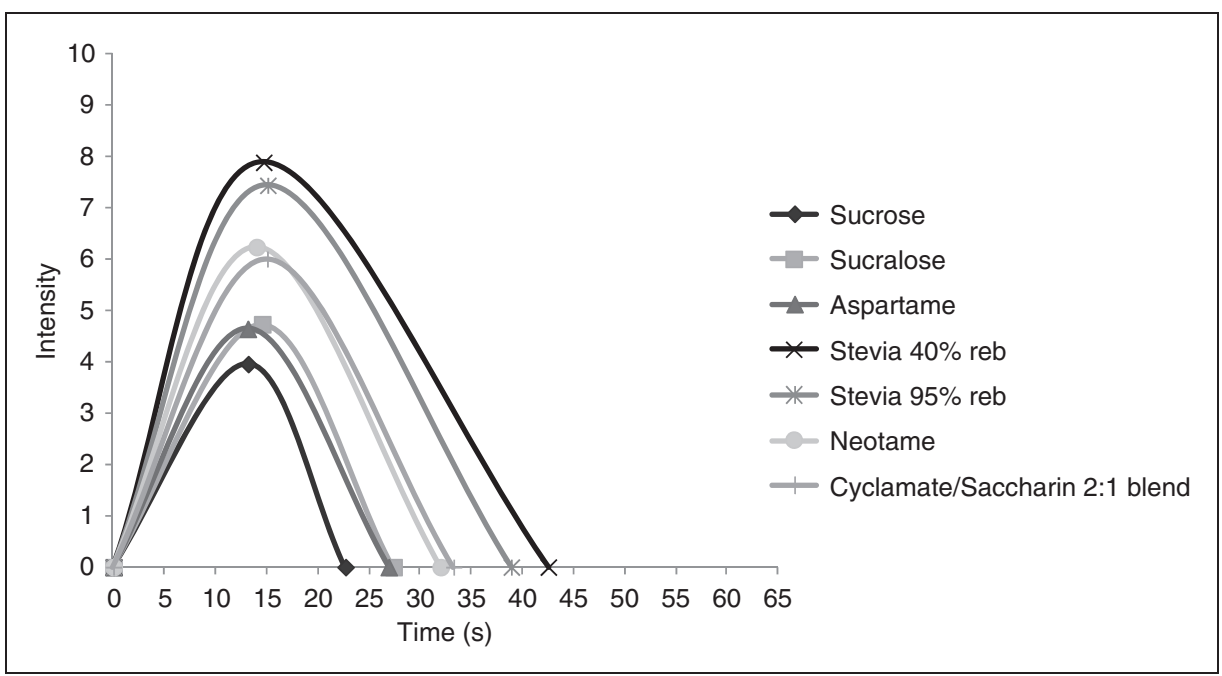

Figure 4. Time-intensity curves and characteristics of bitterness for samples of pitanga nectar.

interfered in the sweet perception of edulcorants obtained from the stevia leaves extract in the pitanga nectar, because it masks the sweetness.

Freitas et al. (2014) previously used and evaluated the pitanga pulp, and they found a $\mathrm{pH}$ of 3.12 and a total titratable acidity of $1.19 \%$ citric acid. Bonnans and Noble (1993) evaluated aqueous solutions which contained sucrose $(8 \%, 10 \%$, and $12 \%)$ and aspartame $(0.06 \%, 0.07 \%$, and $0.08 \%)$, equally sweet, and with the addition of citric acid $(0 \%, 0.075 \%, 0.15 \%$, and $0.225 \%$ ). They consequently observed that the increase in the acid concentration decreased the sweet intensity in all evaluated sucrose and aspartame concentrations.

In a study aimed at evaluating different brands of raspberry-flavored gelatin, both traditional (using sucrose) and diet (using aspartame/acessulfame-potassium and sodium saccharine/sodium cyclamate), by time-intensity analysis for sweet, the results showed that there was no significant difference among all the samples regarding the time in which the maximum intensity of sweetness occurs (Palazzo and Bolini, 2009).

According to Morais et al. (2013), in a study on the replacement of sucrose in gluten-free bread using raw sugar, sucralose, fructose, and stevia, the time-intensity analysis showed that the sample developed with raw sugar had a higher intensity of sweetness.

A time-intensity analysis for the sweetness and bitterness in mango juice was also carried out. The juices were sweetened with cyclamate/saccharin 2:1, aspartame, sucralose, and stevia, all of them replacing sucrose. The sample sweetened with stevia showed the highest intensity and duration for the sweetness and bitterness. Aspartame presented the most similar sensory behavior to that of sucrose through time-intensity analysis (Cavallini and Bolini, 2005).
Palazzo and Bolini (2014) compare the dynamic sensory profile, using time-intensity analysis, of milk chocolate and soy-based chocolates formulated with different sweeteners (sucrose, sucralose, rebaudioside, and neotame). Neotame presented distinct results when comparing its use in milk chocolates to that in soy-based chocolates, and its intensity for sweet taste was greater in the samples containing soybean extract compared to the samples containing dairy. In the milk chocolates, however, neotame provided a dynamic sensory profile with parameter curves closer to those sweetened with sucrose. With respect to rebaudioside, there was an increase in the intensity of bitterness in relation to traditional chocolate.

Thus, it is extremely important to study the behavior of sweeteners in different food matrices, since they differ in behavior, depending on the interactions with the matrix. All cited authors agree that the sample prepared with stevia was the one with highest intensity and duration of bitterness. It is therefore relevant for further studies to investigate this sweetener blended with other that do not show such a marked profile, such as sucralose and aspartame, in order to verify a possible similarity to the sucrose's profile.

\section{CONCLUSION}

The results showed that the samples prepared with sucralose and cyclamate/saccharin 2:1 had more similar sweet profiles to those of the sample prepared with sucrose; also, the samples prepared with sucralose and aspartame showed bitter profiles more similar to that of the sample prepared with sucrose. Thus, sucralose is the most suitable sweetener to replace sucrose in the preparation of the pitanga nectar, because it results in 
a sensorially similar product, whereas with lower calories.

\section{DECLARATION OF CONFLICTING INTERESTS}

The authors declare that there is no conflict of interest.

\section{FUNDING}

The authors acknowledge the financial support from the Conselho Nacional de Desenvolvimento Científico e Tecnológico - $\mathrm{CNPq}-\mathrm{Brazil}$, and the generous cooperation of participating assessors.

\section{REFERENCES}

Alves LR, Battochio JR, Cardoso JMP, De Melo LLMM, Da Silva VS, Siqueira ACP, et al. (2008). Time-intensity profile and internal preference mapping of strawberry jam. Journal of Sensory Studies 23: 125-135.

American Society for Testing and Materials International ASTM International (2011). E1909-11: Standard Guide for Time-Intensity Evaluation of Sensory Attributes. West Conshohocken, PA: Author, pp. 1-15.

Amerine MA, Pangborn RM and Roessler EB. (1965). Principles of Sensory Evaluation of Food. New York: Academic Press, pp. 321-348, 349-397.

Augusto MMM, Queiroz MI and Viotto WH. (2005). Selection and screening of a descriptive panel for evaluation of bitter taste in Brazilian prato cheese. Ciencia e Tecnologia de Alimentos 25(4): 849-852.

Bezerra JEF, Silva Júnior JF and Lederman IE. (2000). Pitanga (Eugenia uniflora L.). Jaboticabal: Funep, 30 p.

Bolini-Cardello HMA, Silva MAAP and Damasio MH. (1999). Measurement of the relative sweetness of stevia extract, aspartame and cyclamate/saccharin blend as compared to sucrose at different concentrations. Plant Foods for Human Nutrition 54: 119-130.

Bonnans S and Noble AC. (1993). Effect of sweetener type and of sweetener and acid levels on temporal perception of sweetness, sourness and fruitiness. Chemical Senses 18: 273-283.

Cadena RS and Bolini HMA. (2011). Time-intensity analysis and acceptance test for traditional and light vanilla ice cream. Food Research International 44: 677-683.

Cardoso JMP and Bolini HMA. (2007). Different sweeteners in peach nectar: Ideal and equivalent sweetness. Food Research International 40: 1249-1253.

Cavallini DCU and Bolini HMA. (2005). Comparação da percepção temporal de doçura, amargor e sabor de fruta em suco de manga reconstituído e adoçado com sacarose, mistura ciclamato/sacarina 2:1, aspartame, sucralose e estévia. Boletim do Centro de Pesquisa de Processamento de Alimentos 23: 361-382.

Cerqueira Júnior NG, Teixeira E and Amboni RDMC. (2007). Método tempo-intensidade: Revisão. Boletim do Centro de Pesquisa de Processamento de Alimentos 25: $1-14$.

Cliff M and Heymann H. (1993). Development and use of time-intensity methodology for sensory evaluation: A review. Food Research International 26: 375-385.
Čmejlová K, Panovská Z, Váchová A and Lukešová D. (2009). Time-intensity studies of sweeteners. Czech Journal of Food Sciences. Special Issue D-Strategies to Improve Food Quality and Safety 27: 327-329.

Damásio MH and Costell E. (1991). Análisis sensorial descriptivo: Generación de descriptores y selección de catadores. Revista Agroquímica de Tecnologia de Alimentos 31: 165-178.

Dijksterhuis GB, Flipsen M and Punter PH. (1994). Principal component analysis of time-intensity data: Three methods compared. Food Quality and Preference 5: 121-127.

Freitas MLF, Dutra MBL and Bolini HMA. (2014). Development of pitanga nectar with different sweeteners by sensory analysis: Ideal pulp dilution, ideal sweetness, and sweetness equivalence. Food Science and Technology 34: $174-180$.

Gomes RP. (1975). Fruticultura brasileira, 2nd ed. São Paulo: Nobel, pp. 384-389.

Goyal SK, Samsher J and Goyal RK. (2010). Stevia (Stevia rebaudiana) a bio-sweetener: A review. International Journal of Food Science and Nutrition 61: 1-10.

Lawless HT and Heymann H. (1999). Sensory Evaluation of Food: Principles and Practices. New York: Aspen Publishers, pp. 265-290.

Lemus-Mondaca R, Vega-Gálvez A, Zura-Bravo L and Kong AH. (2012). Stevia rebaudiana Bertoni, source of a highpotency natural sweetener: A comprehensive review on the biochemical, nutritional and functional aspects. Food Chemistry 132: 1121-1132.

Lima VLAG, Mélo EA and Lima DES. (2002). Total phenolics and carotenoides in surinam cherry. Scientia Agricola 59: 447-450.

Macfie HJ, Bratchell N, Greenhoff K and Vallis LV. (1989). Designs to balance the effect of order of presentation and first-order carry-over effects in hall tests. Journal of Sensory Studies 4: 129-148.

Montijano H, Tomás-Barberán FA and Borrego F. (1998). Propriedades tecnológicas y regulación de los edulcorantes de alta intensidade em la Unión Europea. Food Science and Technology International 4: 5-16.

Moraes PCBT and Bolini HMA. (2010). Different sweeteners in beverages prepared with instant and roasted ground coffee: Ideal and equivalent sweetness. Journal of Sensory Studies 25: 215-225.

Morais EC, Cruz AG and Bolini HMA. (2013). Gluten-free bread: Multiple time-intensity analysis, physical characterisation and acceptance test. International Journal of Food Science and Technology 48: 2176-2184.

Ongaratto RS and Viotto LA. (2009). Clarificação do suco de pitanga (Eugenia uniflora L.) e concentração de carotenóides por microfiltração e ultrafiltração. Brazilian Journal of Food Technology II BMCFB: 85-93.

Palazzo AB and Bolini HMA. (2009). Multiple time-intensity analysis and acceptance of raspberry-flavored gelatin. Journal of Sensory Studies 24: 648-663.

Palazzo AB and Bolini HMA. (2014). Multiple time-intensity analysis: Sweetness, bitterness, chocolate flavor and melting rate of chocolate with sucralose, rebaudioside and neotame. Journal of Sensory Studies 29: 21-32. 
Pinheiro MVS, Oliveira MN, Penna ALB and Tamime AY. (2005). The effect of different sweeteners in low-calorie yogurts - A review. International Journal of Dairy Technology 58: 193-199.

SAS (Statistical Analysis System) (2012). SAS for Windows Version 9.1.3 Service Pack 3. Cary, NC: SAS Institute, Inc.

Silva SM. (2006). Pitanga. Revista Brasileira de Fruticultura 28: $1-159$.

Sinesio F, Moneta E and Esti M. (2005). The dynamic sensory evaluation of bitterness and pungency in virgin olive oil. Food Quality and Preference 16: 557-564.

Sokolowsky M and Fischer U. (2012). Evaluation of bitterness in white wine applying descriptive analysis, timeintensity analysis, and temporal dominance of sensations analysis. Analytica Chimica Acta 732: 46-52.

Souza VR, Pereira PAP, Pineiro ACM, Bolini HMA, Borges SV and Queiroz F. (2013). Analysis of various sweeteners in low-sugar mixed fruit jam: Equivalent sweetness, timeintensity analysis and acceptance test. International Journal of Food Science and Technology 48: 1541-1548.

Stamatis DH. (2002). Six Sigma and Beyond. Design of Experiments. Boca Raton: CRC Press, pp. 122-127.

Techakriengkrain I, Paterson A and Piggotti JR. (2004). Time intensity parameters of sweetness perceptions in lager beers. Journal of the Institute of Brewing 110: 352-359.

Universidade Estadual de Campinas - UNICAMP. (2012). Helena Maria André Bolini. Time-Intensity Analysis of Flavors and Tastes - TIAFT: Software. Registro $\mathrm{n}^{\circ}$ 12445-5, 3 January 2012, 27 March 2012. Revista da Propriedade Industrial n. 2151, p. 178. Rio de Janeiro.

Ye F, Yang R, Hua X, Shen Q, Zhao W and Zhang W. (2014). Modification of steviol glycosides using $\alpha$-amylase. LWT - Food Science and Technology 57: 400-405. 